\title{
Estimation of the Resistivity Index via Nuclear Magnetic Resonance Log Data Based on Fractal Theory
}

\author{
Cheng Feng $\mathbb{D}^{1},{ }^{1}$ Chuang Han, ${ }^{2}$ Wenxing Duan, ${ }^{2}$ Wei Wang, ${ }^{3}$ Yuntao Zhong, ${ }^{1}$ Ziyan Feng, \\ and Ning Zhang ${ }^{1}$
}

${ }^{1}$ Faculty of Petroleum, China University of Petroleum-Beijing at Karamay, Karamay, China
${ }^{2}$ Research Institute of Exploration and Development, Tarim Oilfield Company, PetroChina, Korla, China
${ }^{3}$ Research Institute of Exploration and Development, Xinjiang Oilfield Company, PetroChina, Karamay, China

Correspondence should be addressed to Cheng Feng; fcvip0808@126.com

Received 9 April 2020; Revised 1 October 2020; Accepted 1 December 2020; Published 22 December 2020

Academic Editor: Wei Wei

Copyright ( 2020 Cheng Feng et al. This is an open access article distributed under the Creative Commons Attribution License, which permits unrestricted use, distribution, and reproduction in any medium, provided the original work is properly cited.

\begin{abstract}
The resistivity index is an important parameter for determining the rock saturation index. However, the saturation index changes greatly in unconventional reservoirs, which leads to oil saturation estimation with great difficulty. Hence, we try to establish the relationship between the resistivity index and log data. Firstly, a novel model of estimating the resistivity index with $T_{2}$ time was derived based on fractal theory, the relationship between nuclear magnetic resonance (NMR) $T_{2}$ spectrum and capillary pressure curve $\left(T_{2}-P_{c}\right)$, and Archie formula. It regards the logarithm of the resistivity index as the dependent variable, with $T_{2}$ time and $T_{2}$ time when water saturation is $100 \%$ as the independent variables. Second, 17 cores were drilled, and $T_{2}$ spectrum and the relationship between the resistivity index and water saturation $\left(I_{r}-S_{w}\right)$ were jointly measured. Next, the experimental results were substituted into the established model to get the model parameters via the multivariate statistics regression method. Then, the experimental data engaged and not engaged in modeling were used to test the established model. The average relative errors of estimated resistivity indices and experimental results are smaller than $8 \%$, and those of the regressed saturation index are smaller than 5\%. Finally, the established model was applied in log data processing and interpretation with good effects. It thus proves that the method of the estimating resistivity index with $T_{2}$ time is reliable, which provides a novel solution for determining rock electrical parameter of unconventional reservoirs.
\end{abstract}

\section{Introduction}

The saturation model has always been a puzzle troubling petrophysicists. In the classical rock saturation model, the saturation index has always been an indispensable parameter [1-3]. It is obtained by regression of the $I_{r}-S_{w}$ relationship. Therefore, the accurate resistivity index is very important.

In previous researches, the saturation index is usually obtained through the measured $I_{r}-S_{w}$ relationship by regression [4-6]. One saturation index is used in the same studied interval. This way of acquiring results features high accuracy and witnesses good application effect in conventional reservoirs. However, as the main research object turns to unconventional reservoirs, the complicated lithology and pore structure lead to wider variation range of the saturation index. Moreover, the rock electrical experiment becomes more difficult, and the unified saturation index by experiment will bring great error to the evaluation of oil saturation [7]. Hence, in recent years, petrophysicists try to establish the relationship between the resistivity index and well log data, for the purpose of continuously calculating the saturation index.

The basis of the method is that there is certain relationship between the pore structure and conductive property of the rock [8-10]. According to the Archie formula, the resistivity index can be expressed as the quantitative function of water saturation. Meanwhile, previous researches indicate that capillary pressure can also be expressed as the function of wetting-phase saturation. It can either be the linear relationship based on the capillary model [11], or the power function relationship by fractal theory [12, 13]. Besides, Longeron et al. also carried out experimental analysis on this [14]. According to fractal theory, Ge et al. acquired the 
relationship between the resistivity index and capillary pressure $\left(I_{r}-P_{c}\right)$ through experimental data fitting [15]. However, it was not applied in log data processing and interpretation. As a result, it is feasible to try to establish the $I_{r}-P_{c}$ relationship $[12,13]$. Although capillary pressure is only an experimental data, the reconstruction of pseudocapillary pressure curve with NMR data has been a very mature technology $[16,17]$. Therefore, petrophysicists are also trying to establish the relationship between the resistivity index and $T_{2}$ time for realizing the estimation of the resistivity index via log data [18-20].

In order to obtain the relationship mentioned above, the model of the estimating resistivity index using $T_{2}$ time and $T_{2}$ time when water saturation is $100 \%$ was first derived based on fractal theory, $T_{2}-P_{c}$ relationship, and Archie formula. Then, the cores acquired from the study area were analyzed, and the above model is calibrated by the experimental data. Finally, the modeling data, the data not engaged in modeling, and the actual log data were used to test the application effect of the model, respectively, from three aspects.

\section{Methodology}

2.1. Geological Background. Ordos basin, located in North China (Figure 1(a)), is a sedimentation basin and rich in oil and gas resources [22]. According to basement property, tectonic evolution, and current tectonic pattern of the basin, it can be divided into 6 first-order tectonic units (Figure 1(b)). The internal structure is relatively simple with a stable formation and the inclination angle less than $1^{\circ}$ generally, while the disrupted fold is relatively developed along the margin of the basin [23-25]. The study area is at the lower-middle parts of the border between Tianhuan depression and North Shaanxi slope, which extends from Dingbian county in the north to Zhenyuan county in the south and stretches from Mahuang mountain in the west to Youfangzhuang village in the east across the Tianhuan depression tectonic belt (Figure 1(b)). The study area is the Chang 8 stratum, being the main pay zone of Triassic Yanchang formation (Figure 1(c)). In the sedimentation stage of Chang 8 stratum, it is located at a relatively stable structural environment-a typical shallow water delta sedimentation. The distribution of the sand body has a characteristic that partial thick sand body along the direction of the river channel is distributed in a cuspate shape. The fine sandstone, siltstone, and mudstone are the main lithology. The porosity and permeability are within the range of $6 \%-14 \%$ and $0.05 \times 10^{-3}$ $\mu \mathrm{m}^{2}-1 \times 10^{-3} \mu \mathrm{m}^{2}$, respectively, which belongs to a typical tight sandstone reservoir.

2.2. Estimation of the $I_{r}-S_{w}$ relationship based on NMR $T_{2}$ spectrum. Based on fractal theory, Toledo et al. and Li and Williams considered that rock resistivity bears the following relationship with the corresponding wetting-phase saturation $[12,13]$ :

$$
\frac{1}{R_{t}} \propto\left(S_{w}\right)^{\frac{1}{\beta\left(3-D_{f}\right)}},
$$

where $R_{t}$ refers to rock resistivity, $\Omega \bullet \mathrm{m} ; S_{w}$ refers to water (wetting-phase) saturation, $\% ; \beta$ refers to a model coefficient, irrelevant to water film thickness and dimensionless; $D_{f}$ refers to fractal dimension, dimensionless.

Besides, Toledo et al. and Li and Williams together considered that the wetting-phase saturation of the rock and the corresponding capillary pressure satisfy the fractal theory $[12,13]$, as shown in the following relationship:

$$
S_{w} \propto\left(P_{c}\right)^{-\left(3-D_{f}\right)},
$$

where $P_{c}$ indicates the capillary pressure, $\mathrm{MPa}$.

There have been a lot of publications to discuss how to reconstruct capillary pressure curve by using $T_{2}$ spectrum based on the former research results, and the technique seems to run smoothly [26-28]. Scholars believe that on the premise of fixed wetting-phase saturation [17], there is an obvious power function relationship between the $P_{c}$ and $T_{2}$ time, as shown in Eq. (3):

$$
P_{c}=m \times\left(\frac{1}{T_{2}}\right)^{n *},
$$

where $T_{2}$ indicates the transversal relaxation time, ms; $m$ and $n^{*}$ mean the model coefficient, which are dimensionless.

Equation (1), Eq. (2), and Eq. (3) have been verified by petrophysical experimental results in different study areas. Equation (4) can be obtained in combination of Eq. (1), Eq. (2), and Eq. (3) under the fixed wetting-phase saturation.

$$
R_{t} \propto\left(\frac{C}{T_{2}}\right)^{\frac{n *}{\beta}},
$$

where $C$ is a constant, dimensionless.

Equation (4) reflects that the rock resistivity and $T_{2}$ time conform to the relationship mentioned above with the fixed wetting-phase saturation. Therefore, when the wettingphase saturation is $100 \%$, Eq. (4) can be expressed as Eq. (5).

$$
R_{0} \propto\left(\frac{C}{T_{2, S_{w}=100 \%}}\right)^{\frac{n *}{\beta}}
$$

where $T_{2, S w=100 \%}$ indicates the corresponding $T_{2}$ time under water-saturated condition, $\mathrm{ms} ; R_{0}$ refers to the rock resistivity under water-saturated condition, $\Omega \bullet m$.

Equation (6) can be obtained by combining Eq. (4) and Eq. (5) under the fixed wetting-phase saturation.

$$
\frac{R_{t}}{R_{0}}=A \times\left(\frac{T_{2} *}{T_{2, S w=100 \%}}\right)^{-\frac{n *}{\beta}},
$$

where $A$ indicates the model coefficient, which is dimensionless; $T_{2}{ }^{*}$ indicates the corresponding $T_{2}$ time under the fixed wetting-phase saturation, ms. 


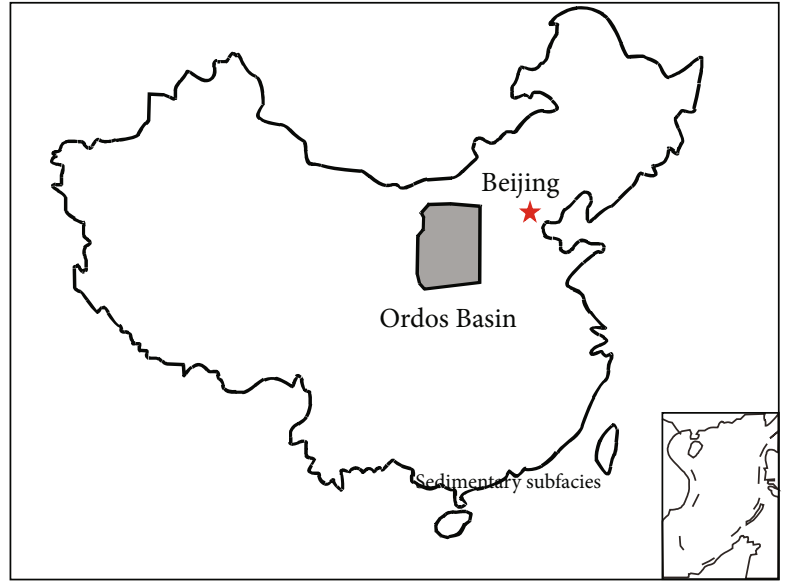

(a)

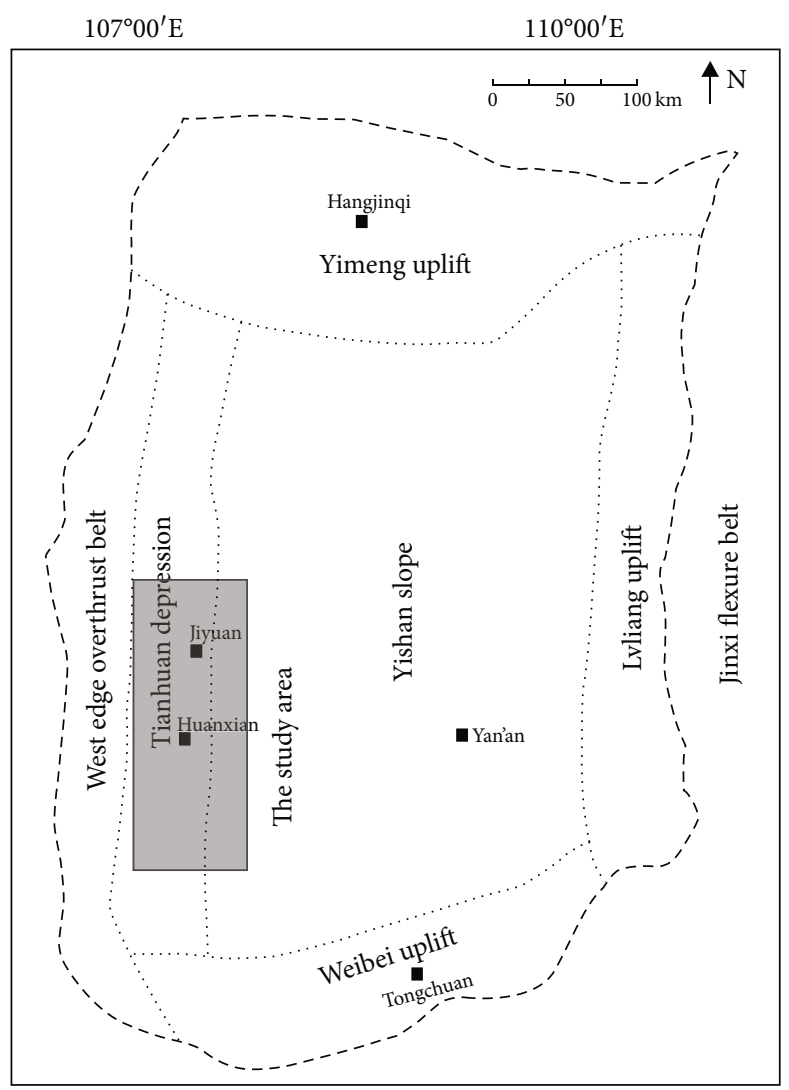

$\square$ Study area

- - - Basin boundary

..... Tectonic subregions

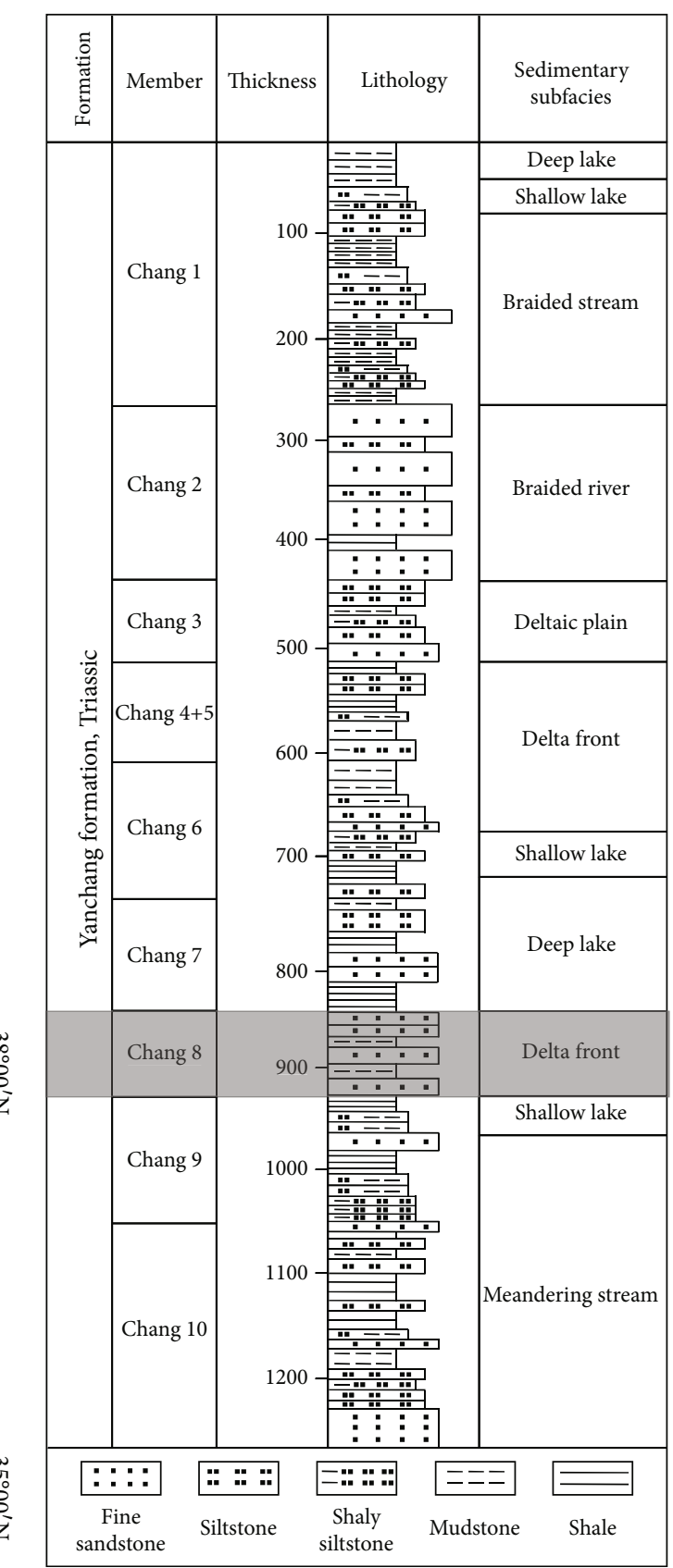

(c)

FIgURE 1: Location of the study area [21].

According to the Archie formula [(1)], the resistivity index can be expressed by Eq. (7).

$$
I=\frac{R_{t}}{R_{0}},
$$

where $I$ indicates the resistivity index, which is dimensionless.
In fact, in the water-saturated state, $R_{t}$ equals to $R_{0}(I=1)$, which have similar physical significance. Hence, at this time, $I$ is an independent variable. However, in other states, the value of $I$ is related to petrophysical properties of rock, and it becomes dependent.

Under the fixed saturation, substitute Eq. (6) into Eq. (7) and take the same logarithm based on 10 on both ends of the new equation to obtain Eq. (8). 

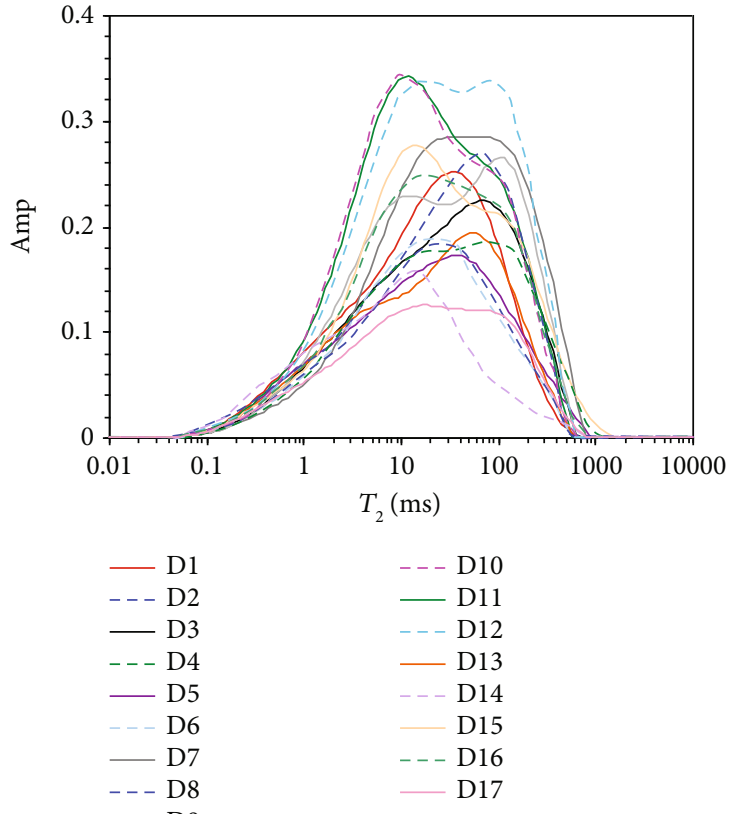

Figure 2: The experimental data of $T_{2}$ spectrum under watersaturated condition.

$$
\lg (I)=\frac{n *}{\beta} \times\left(\lg \left(T_{2, S w=100 \%}\right)-\lg \left(T_{2} *\right)\right)+\lg (A)
$$

For the convenience of parameter regression, we define

$$
\begin{gathered}
\gamma=\frac{n *}{\beta}, \\
E=\lg (A),
\end{gathered}
$$

where $\gamma$ and $E$ indicate the model coefficient, which is dimensionless.

Equation (11) can be obtained by combining Eq. (8), Eq. (9), and Eq. (10). There is a linear relationship between $\lg (I)$ and $\lg \left(T_{2, S w=100 \%} / T_{2} *\right)$ with $\gamma$ as slope and $E$ as intercept obviously.

$$
\lg (I)=\gamma \times \lg \left(\frac{T_{2, S w=100 \%}}{T_{2} *}\right)+E,
$$

where $\gamma$ and $E$ are obtained directly by model fitting between the raw data of the $T_{2}$ spectrum and the values of $I$.

\section{Results and Discussions}

3.1. Experimental Data. To establish the quantitative relationship between the resistivity index and $T_{2}$ spectrum, 17 sandstone cores (D1, D2...D17) were drilled in the study area. After processing, core plungers with length of about $4 \mathrm{~cm}$ and diameter of 1 inch were formed, respectively. They are complete and strong bonding with no fragmentation. The distribution scopes of porosity and permeability are 6.03\%$14.13 \%$ and $0.02 \times 10^{-3} \mu \mathrm{m}^{2}-1.34 \times 10^{-3} \mu \mathrm{m}^{2}$, respectively. $\mathrm{NaCl}$ solution was prepared based on the average salinity of

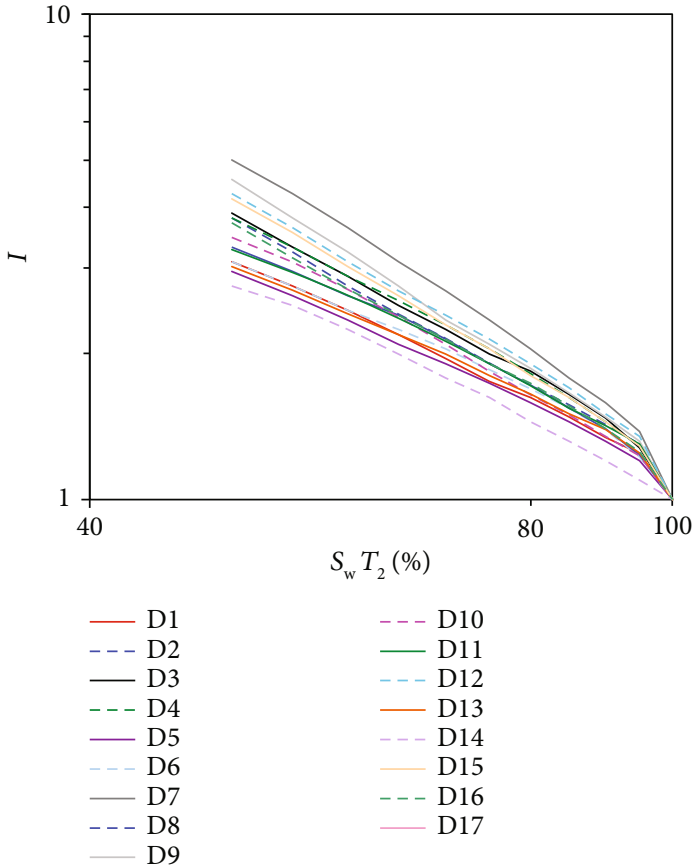

Figure 3: The experimental data of the $I_{r}-S_{w}$ curve.

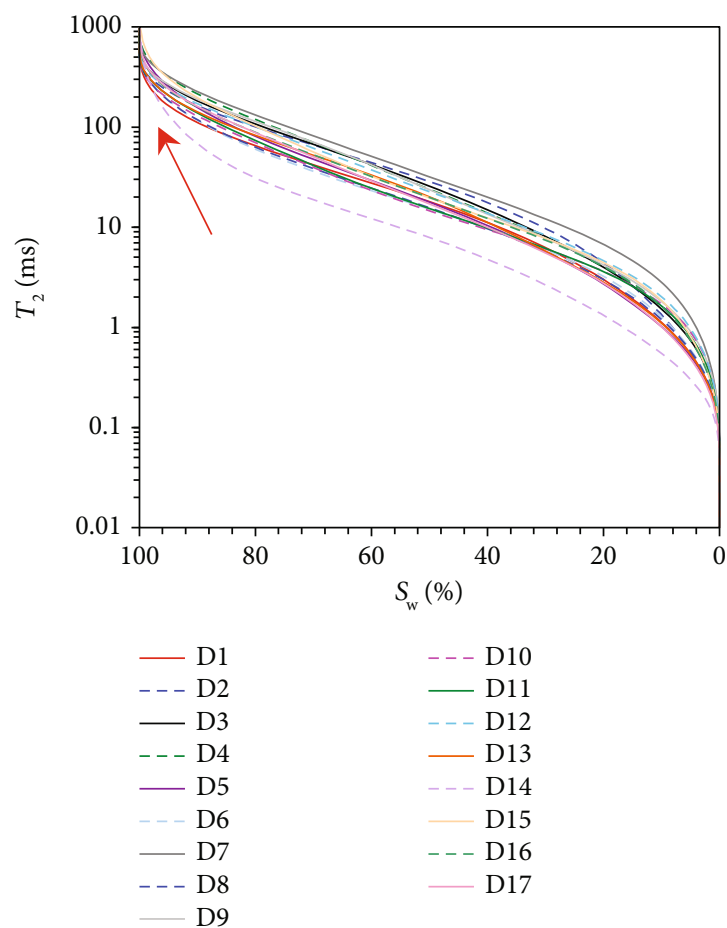

FIgURE 4: The cumulative curves converted by the measured $T_{2}$ spectra.

formation water as the experimental water. After the preparation of experimental materials, the cores were saturated with experimental water. The $T_{2}$ spectra under watersaturated condition were measured by the MARAN DRX2 experiment device manufactured by Oxford Instruments. The experimental data are shown in Figure 2. Then, the resistivity indices under different water saturations by gas 


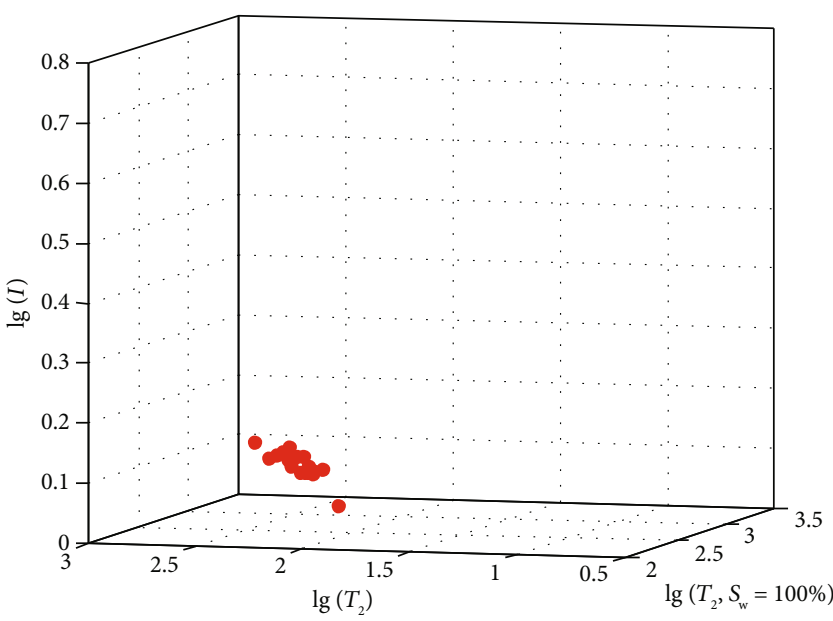

(a) $S_{w}=95 \%$

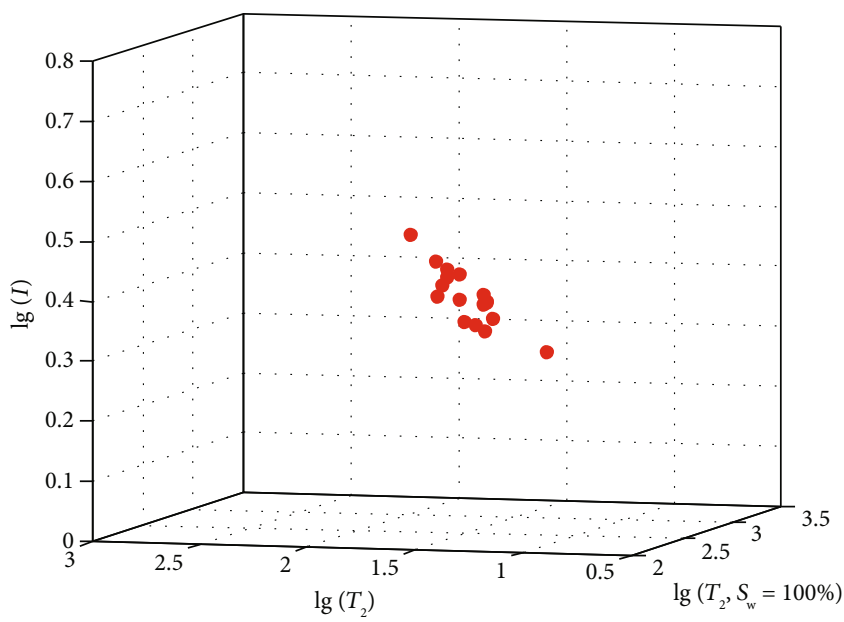

(c) $S_{w}=65 \%$

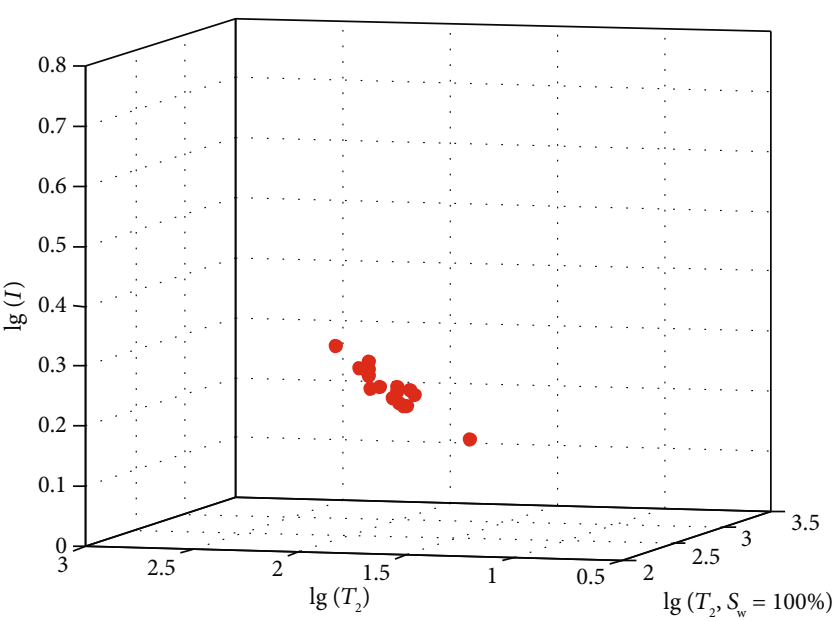

(b) $S_{w}=80 \%$

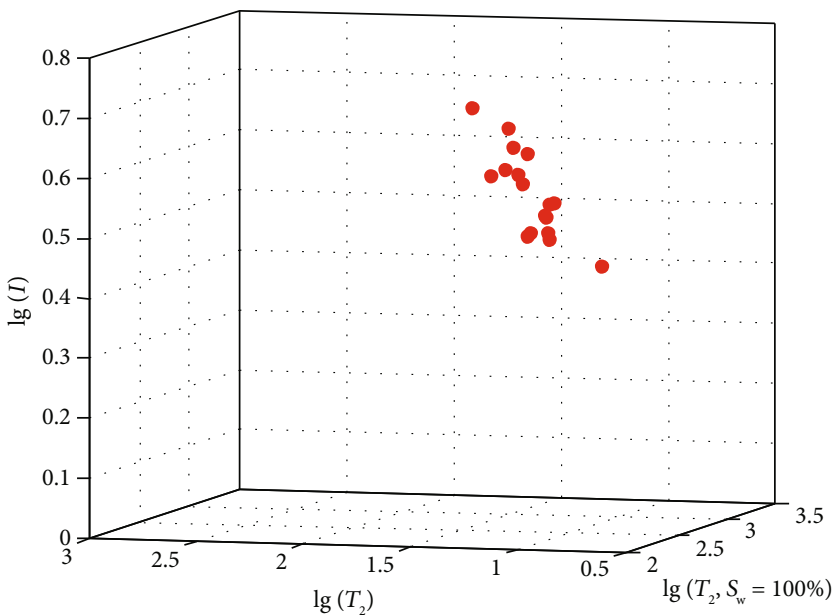

(d) $S_{w}=50 \%$

FIgure 5: The correlation between the resistivity index, $T_{2}$ time, and $T_{2}$ time when the water saturation is $100 \%$ of different cores. (a)-(d) represent that water saturation equals to $95 \%, 80 \%, 65 \%$, and $50 \%$, respectively.

TABLE 1: The models for predicting the resistivity index from $T_{2}$ time and $T_{2}$ time when the water saturation is $100 \%$.

\begin{tabular}{llr}
\hline Water saturation & Models & Correlation coefficient \\
\hline $95 \%$ & $\log _{10}(I(i))=0.192 \times \log _{10}\left(T_{2}(i)\right)-0.192 \times \log _{10}\left(T_{2, S_{w}=100 \%}\right)+0.166$ & 0.81 \\
$80 \%$ & $\log _{10}(I(i))=0.229 \times \log _{10}\left(T_{2}(i)\right)-0.229 \times \log _{10}\left(T_{2, S_{w}=100 \%}\right)+0.417$ & 0.92 \\
$65 \%$ & $\log _{10}(I(i))=0.276 \times \log _{10}\left(T_{2}(i)\right)-0.276 \times \log _{10}\left(T_{2, S_{w}=100 \%}\right)+0.689$ & 0.85 \\
$50 \%$ & $\log _{10}(I(i))=0.411 \times \log _{10}\left(T_{2}(i)\right)-0.411 \times \log _{10}\left(T_{2, S_{w}=100 \%}\right)+1.138$ & 0.81 \\
\hline
\end{tabular}

displacing water were measured. As shown in Figure 3, the saturation indices obtained by regression based on the power function are distributed in 1.47-2.16. It reflects that the measured saturation index is of large change scope, and great errors can be caused if the average value is taken in the study area.

3.2. Determination of the $T_{2}$ Time when the Water Saturation Is $100 \%$. According to Eq. (11), it will have a great influence on the model accuracy to acquire the accurate $T_{2}$ time when the water saturation is $100 \%$. In Figure 2, each NMR curve represents a core under the condition of saturated water. The integrals of these NMR curves were computed from small $T_{2}$ time to big $T_{2}$ time that correspond with the $x$ -axis, which reflected the amount of pore water is more and more. Convert the measured $T_{2}$ spectrum into a cumulative curve (Figure 4) on the basis of the experimental results in Figure 2. As shown in the position indicated by the arrow, read the corresponding value on the $y$-axis when the value of the $x$-axis is $100 \%$. This value is namely the corresponding $\mathrm{T}_{2}$ time when the water saturation is $100 \%$. 


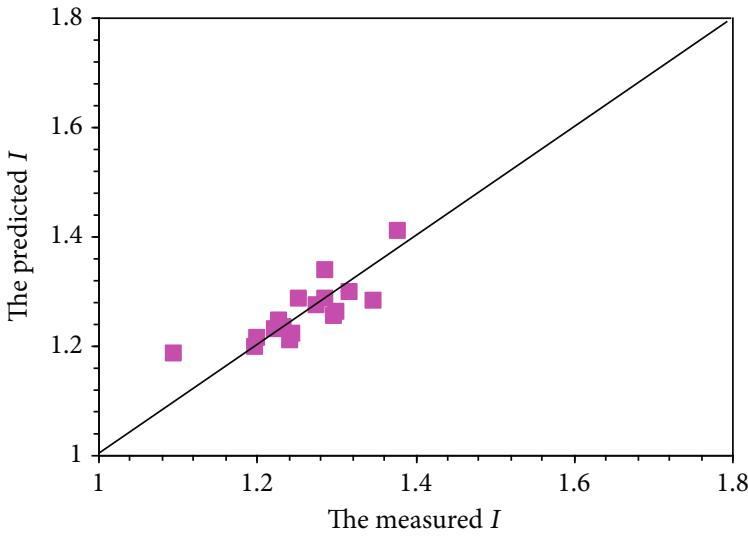

(a)

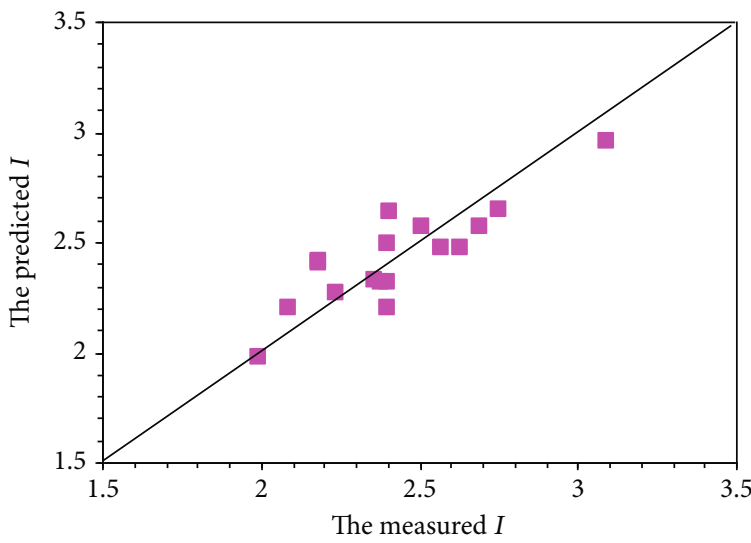

(c)

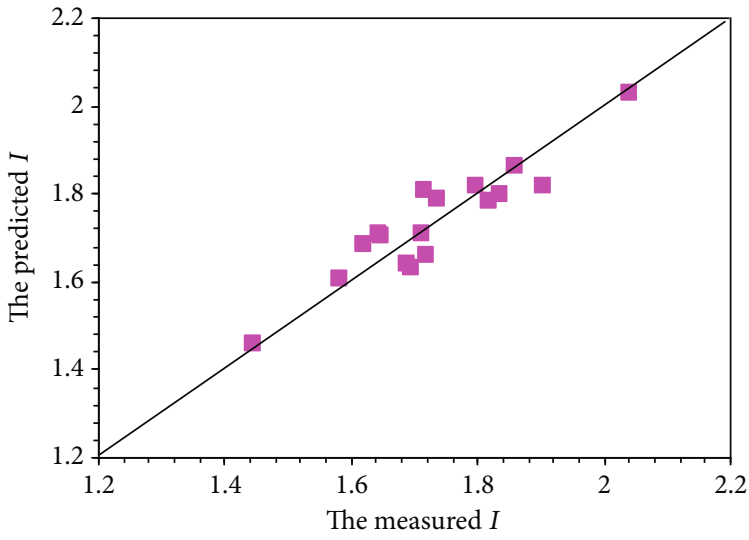

(b)

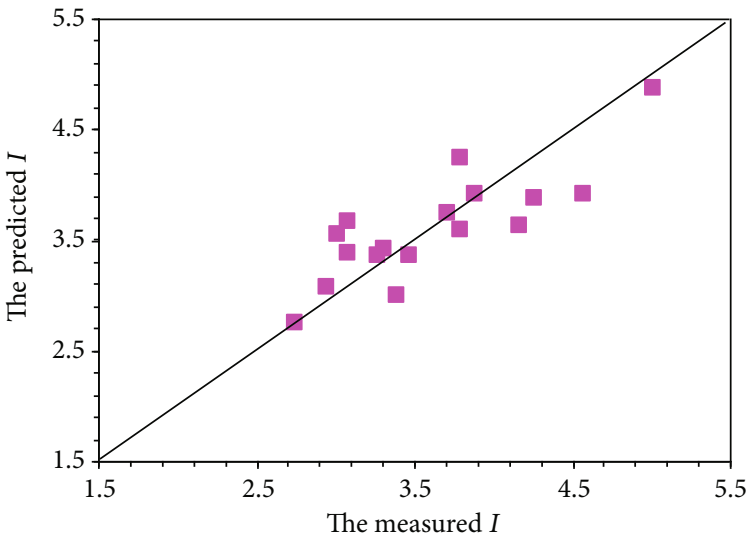

(d)

FIGURE 6: The comparison results of the measured and predicted resistivity indices. (a)-(d) represent that water saturation equals to $95 \%$, $80 \%, 65 \%$, and $50 \%$, respectively.

3.3. Model Establishment. During experimental measurement, the $I_{r}-S_{w}$ in Figure 3 is different from the sampling point on the cumulative curve of $T_{2}$ spectrum in Figure 4 . Hence, unify the sampling points of the two figures prior to the model establishment. Set a fixed water saturation value. Then make statistics, respectively, for the resistivity index in correspondence to different water saturation in Figure 3 and the $T_{2}$ time in correspondence to different water saturation in Figure 4. Take logarithm based on 10, respectively, to form a data set for calibrating the model established in Eq. (11).

After the establishment of data set, draw the 3D scatter diagram to present visually. As shown in Figure 5, $x$ -axis, $y$-axis and $z$-axis represent, respectively, the value of three parameters after taking the logarithm. It is obvious that in a three-dimensional space, data points form in a similar but not exactly the same tendency under different water saturations. When the water saturation is reduced, the data point is more scattered relatively. Therefore, substitute the data point under different water saturations in Figure 5 into Eq. (11), respectively. Obtain the model parameters $\gamma$ and $E$ under different water saturations by multivariate statistics regression [22]. As shown in Table 1, the related coefficients of the model are greater
TABLE 2: The average values and relative errors of the predicted and measured resistivity indices.

\begin{tabular}{lccc}
\hline $\begin{array}{l}\text { Water } \\
\text { saturation }\end{array}$ & $\begin{array}{c}\text { Average predicted } \\
\text { resistivity indices }\end{array}$ & $\begin{array}{c}\text { Average measured } \\
\text { resistivity indices }\end{array}$ & $\begin{array}{c}\text { Average } \\
\text { relative } \\
\text { errors }\end{array}$ \\
\hline $95 \%$ & 1.2590 & 1.2610 & $2.29 \%$ \\
$80 \%$ & 1.7339 & 1.7347 & $2.49 \%$ \\
$65 \%$ & 2.4248 & 2.4291 & $4.81 \%$ \\
$50 \%$ & 3.6050 & 3.6220 & $7.56 \%$ \\
\hline
\end{tabular}

than 0.8 , indicating a better fitting effect and higher model accuracy.

According to the above theoretical model analysis, experimental data presentation (Figure 5), and models established (Table 1), there is a quantitative relationship as shown in Eq. (11) and Table 1 among the resistivity index, the $T_{2}$ time of corresponding saturation, and the $T_{2}$ time when the water saturation is $100 \%$. The proposed models are supported by the modeling data.

3.4. Model Test. To test the reliability of models established in Table 1, this paper sets forth from two aspects. First, judge 


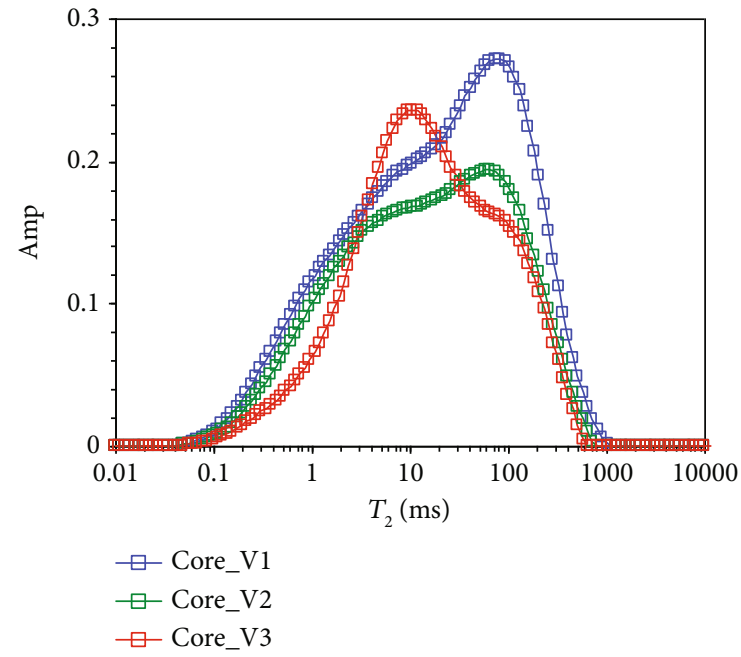

(a)

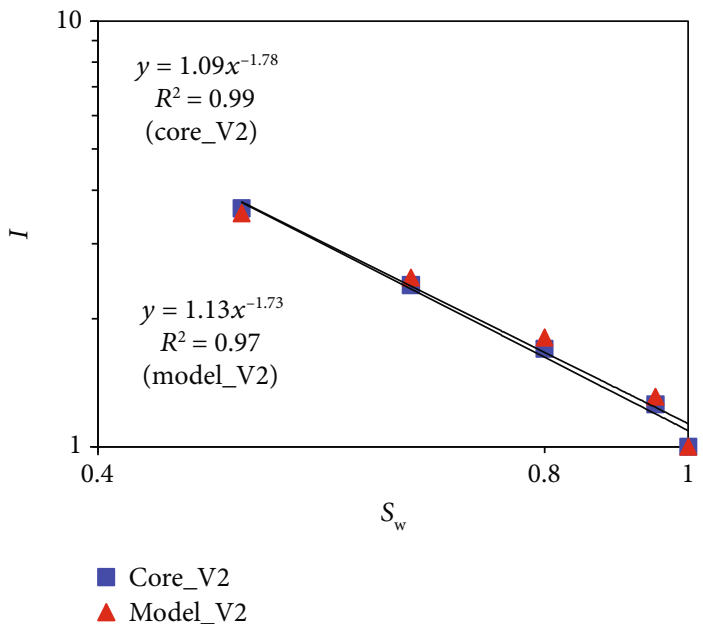

(c)

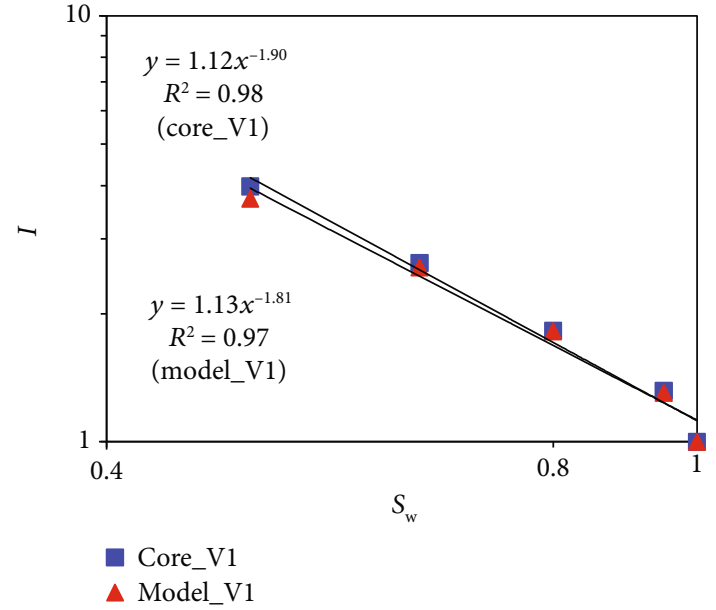

(b)

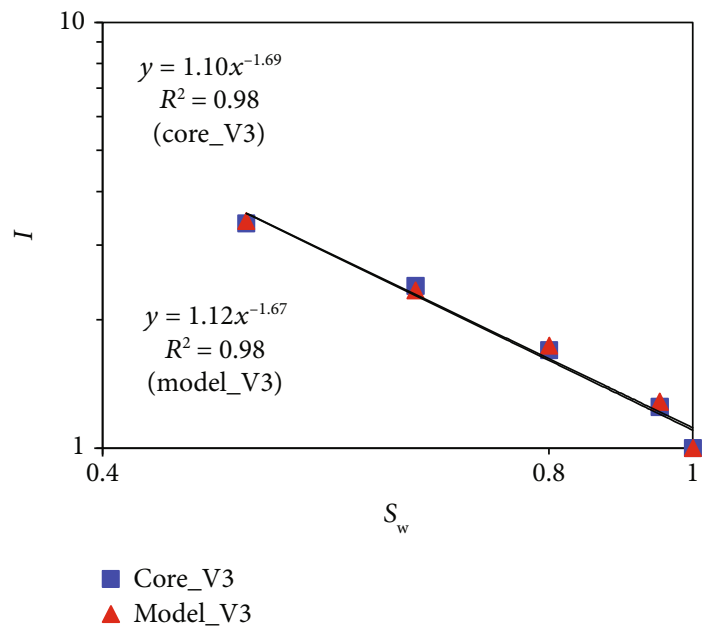

(d)

Figure 7: The comparison results of the measured and predicted $I-S_{w}$ (a) represents the $T_{2}$ spectra of three cores under water-saturated condition. (b)-(d) represent the comparison results of cores V1, V2, and V3, respectively.

the resistivity indices of cores involved in the model establishment with the established models. Then, estimate the resistivity index and saturation index of cores not involved in the model establishment with the established models.

As can be seen from Figures 2 and 3, the experimental results of 17 cores were used for modeling based on Table 1. Under the condition of fixed water saturation, $T_{2}$ time and $T_{2}$ time when the water saturation is $100 \%$ in the modeling data set were, respectively, substituted into the models established in Table 1 to estimate the resistivity indices of 17 cores under different water saturation states. Then, the estimated resistivity indices and the measured results were analyzed by cross plot, as shown in Figure 6 . The ordinate refers to the estimated resistivity index, and the abscissa refers to the measured one. When water saturation is less than $80 \%$, most of the data points are distributed near the diagonal, which indicates that the estimated resistivity indices are close to the experimental results. When the water saturation is $95 \%$, a small amount of estimated results is significantly different from the measured results, which may be the interference caused by measurement error. Table 2 lists the average values and average relative errors between the estimated and measured resistivity indices under the condition of fixed water saturation. As seen from the table, the average values are very consistent, and the average relative errors are less than $8 \%$, indicating that the estimated results are consistent with the measured ones.

Figure 7 (a) shows the $T_{2}$ spectrum experimental results of 3 cores not used for modeling. First, the $T_{2}$ spectra in Figure 7 (a) were converted into the cumulative distribution curves by the order of water saturation from low to high. $\mathrm{T}_{2}$ time corresponding to the set water saturation $(95 \%$, $80 \%, 65 \%, 50 \%)$ and $T_{2}$ time when the water saturation is $100 \%$ on the cumulative distribution curve were read, respectively. Then, they were, respectively, substituted into Table 1 to calculate the resistivity indices under different water saturation states. As shown in Figures 7(b)-(d), the estimated and measured $I_{r}-S_{w}$ relationships were analyzed by cross 
TABLE 3: The comparison results of the measured and predicted rock electrical parameters.

\begin{tabular}{lcccccc}
\hline No. & $b \_c o r e$ & $b \_$model & Relative errors of $b$ & $n \_c o r e$ & $n \_$model & Relative errors of $n$ \\
\hline V1 & 1.12 & 1.13 & $0.89 \%$ & 1.90 & 1.81 & $4.74 \%$ \\
V2 & 1.09 & 1.13 & $3.67 \%$ & 1.78 & 1.73 & $2.81 \%$ \\
V3 & 1.10 & 1.12 & $1.82 \%$ & 1.69 & 1.67 & $1.18 \%$ \\
\hline
\end{tabular}

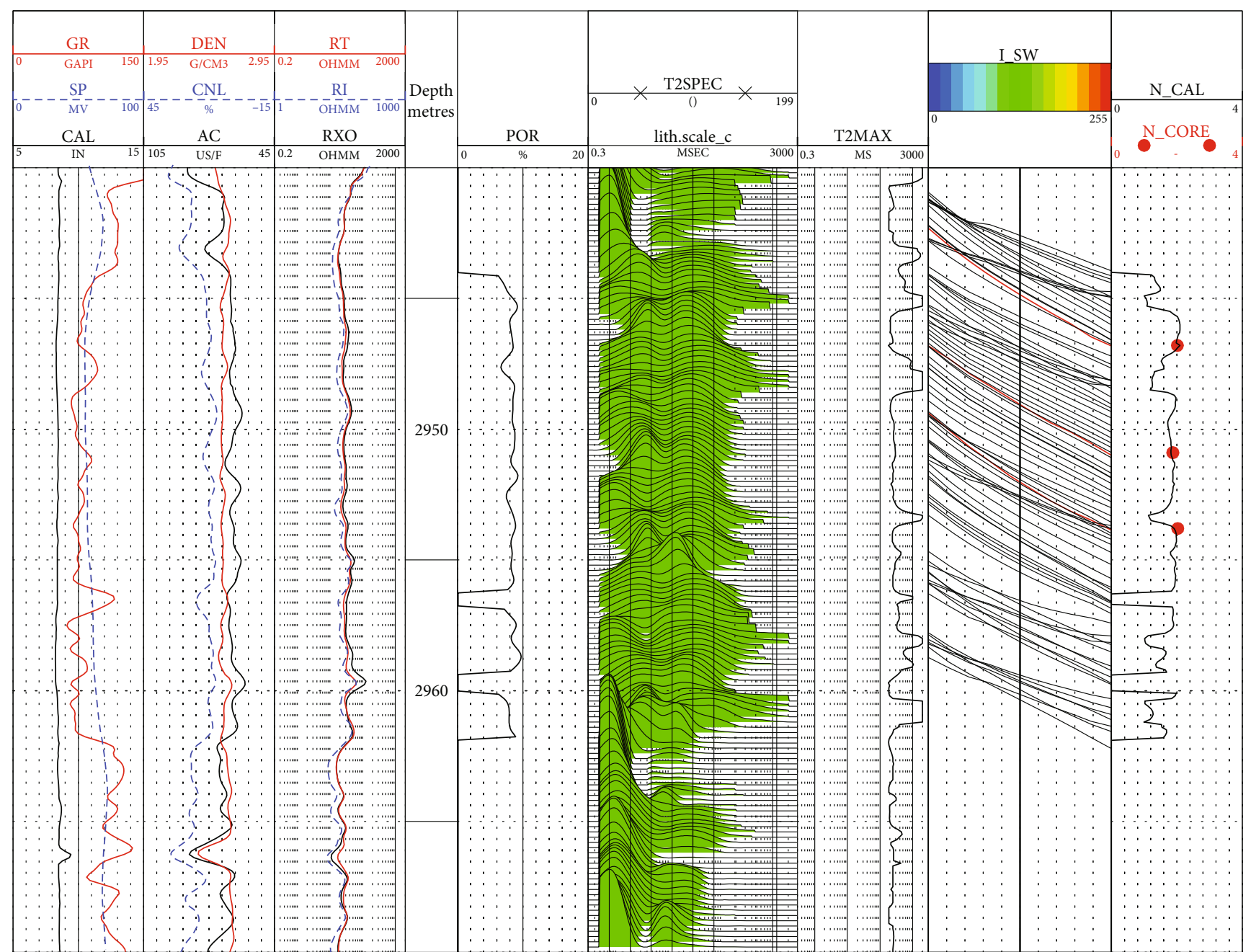

Figure 8: A field study of the proposed model for resistivity prediction via $T_{2}$ spectrum.

plot; wherein, the three figures represent cores V1, V2, and V3, respectively. As can be seen from them, the estimated data points (red) almost coincide with the measured data points (blue), indicating both results are in high consistency. In addition, the regressed and measured rock electrical parameter $b$ and saturation index $n$ are shown in Table 3 . The estimated results of the no matter rock electrical parameter $b$ or saturation index $n$ are in high consistency with the measured results, showing that the relative error is basically below $5 \%$.

Whether through the experimental results involved in modeling or the ones not involved in modeling, the test results of the model are good, indicating that the estimation model established is reliable.
3.5. Analysis of the Application Effect. The above results show that the established estimation model of the resistivity index is reliable from the point of view of the core. Now it is analyzed with actual log data from a water layer. Figure 8 is a $\log$ interpretation result of well $B$ in the study area. In the figure, the first track is the lithologic logs (natural gamma ray curve, spontaneous potential curve, and caliper curve); the second one is the porosity logs (density curve, neutron porosity curve, and acoustic curve); the third one is the resistivity logs (deep, medium, and shallow resistivity curves); the fifth one is the porosity curve calculated by density log data; the sixth one is the NMR log curve; the seventh one is $T_{2}$ time calculated when the water saturation is $100 \%$; the eighth one is the $I_{r}-S_{w}$ relationship curve; and the ninth one is the 
saturation index curve. Among them, the black curves in the eighth and ninth tracks are the results estimated by the established model, and the red curves and scatter points in both tracks are the analysis results of the core experiment. As seen from Figure 8, the $I_{r}-S_{w}$ relationship curves estimated in the eighth track have the same trend as the analysis results of the core experiment, with similar curve shape and good coincidence. The errors between the predicted and measured saturation indices in the ninth track are very small.

To sum up, it is feasible to estimate the resistivity index by $T_{2}$ spectrum. Furthermore, the established estimation model is reliable.

\section{Conclusions}

Based on fractal theory, $T_{2}-P_{c}$ relationship, and Archie formula, a corresponding model is derived, which regards the logarithm of the resistivity index as the dependent variable and regards $T_{2}$ time and $T_{2}$ time when the water saturation is $100 \%$ as the independent variable. The model parameters under different water saturation states were obtained by the multivariate statistical regression method, in combination with the NMR $T_{2}$ spectra and $I_{r}-S_{w}$ relationships of 17 cores in the study area. Then, the reliability of the models was verified by experimental results of modeling data and nonmodeling data, with errors of less than $8 \%$ and $5 \%$. Finally, the processing and interpretation results of the actual log data further verify the good application effect of the models. It thus proves that the method of the estimating resistivity index with $T_{2}$ time is reliable, which provides a novel solution for determining the rock electrical parameter of unconventional reservoirs.

\section{Nomenclature}

\begin{tabular}{|c|c|}
\hline$R_{t}:$ & $\begin{array}{l}\text { Deep lateral resistivity, can measure the undis- } \\
\text { turbed formation, } \Omega \cdot \mathrm{m}\end{array}$ \\
\hline$R_{0}:$ & $\begin{array}{l}\text { Rock resistivity under water-saturated condition, } \\
\Omega \cdot \mathrm{m}\end{array}$ \\
\hline$S_{w}:$ & Water saturation, \% \\
\hline$D_{f}:$ & Fractal dimension, dimensionless \\
\hline$P_{c}:$ & Capillary pressure, Mpa \\
\hline$m:$ & $\begin{array}{l}\text { The index of pore structure related to formation } \\
\text { factors by Archie formula, dimensionless }\end{array}$ \\
\hline$n *:$ & $\begin{array}{l}\text { The saturation index associated with the resis- } \\
\text { tance increase index in The Archie formula, } \\
\text { dimensionless }\end{array}$ \\
\hline$T_{2}:$ & $\begin{array}{l}\text { Transverse relaxation time used to characterize } \\
\text { the decay of the NMR spin-echo signal, s }\end{array}$ \\
\hline$T_{2, S w=100 \%}$ & $\begin{array}{l}\text { Corresponding T2 time under water-saturated } \\
\text { condition, s }\end{array}$ \\
\hline$I:$ & $\begin{array}{l}\text { Resistivity index in Archie formula, } \\
\text { dimensionless }\end{array}$ \\
\hline
\end{tabular}

\section{Data Availability}

The data used but not presented in the manuscript will be provided on request.

\section{Conflicts of Interest}

The authors declare that they have no conflicts of interest.

\section{Acknowledgments}

Research for this paper was supported by the National Natural Science Foundation of China (No. 42004089), the Major National Oil \& Gas Specific Project of China (No. 2016ZX05050008), the Natural Science Foundation of Xinjiang Uygur Autonomous Region (No. 2017D01B57), the Natural Science Project of Xinjiang Uygur Autonomous Region Education Department (No. XJEDU2017S063, XJEDU2019Y070), the Young Elitist Scientific Research Project of China University of Petroleum, Beijing at Karamay (No. BJRC20170001), and the Scientific Research Starting Foundation of China University of Petroleum, Beijing at Karamay (No. RCYJ2016B-01-008).

\section{References}

[1] G. E. Archie, "The electrical resistivity log as an aid in determining some reservoir characteristics," Transactions of the AIME, vol. 146, no. 3, pp. 54-61, 2013.

[2] M. H. Waxman and L. J. M. Smits, "Electrical conductivities in oil-bearing shaly sands," SPE Journal, vol. 8, no. 8, pp. 107-122, 1968.

[3] C. Clavier, G. Coates, and J. Dumanoir, "Theory and experimental basis for the dual-water model for interpretation of shaly sands," SPE Journal, vol. 24, no. 2, pp. 153-168, 1984.

[4] W. G. Anderson, "Wettability literature survey-part 2: wettability measurement," Journal of Petroleum Technology, vol. 38, no. 11, pp. 1246-1262, 1986.

[5] Z. Q. Mao, C. G. Zhang, and C. Z. Lin, "The effect of wettability of reservoir on the log derived water saturation," Well Logging Technology, vol. 21, no. 1, pp. 50-54, 1997.

[6] C. Feng, Z. Mao, W. Yin et al., "An experimental study on resistivity and conductive mechanism in low-permeability reservoirs with complex wettability," Chinese Journal of Geophysics, vol. 60, no. 2, pp. 164-173, 2017.

[7] L. Zhu, C. Zhang, C. Zhang et al., "Challenges and prospects of digital core-reconstruction research," Geofluids, vol. 2019, 29 pages, 2019.

[8] L. Z. Xiao, NMR Image Logging and NMR in Rock Experiments, Science Press, Beijing, 1998.

[9] L. M. Zhang and Y. J. Shi, "On Archie's electrical parameters of sandstone reservoir with complicated pore structures," Well Logging Technology, vol. 29, no. 5, pp. 446-448, 2005.

[10] X. Ge, Y. Fan, D. Yang, H. Hu, and S. Deng, "Study on the influential factors of saturation exponent based on the equivalent rock element theory," Oil Geophysical Prospecting, vol. 46, no. 3, pp. 477-481, 2011.

[11] M. Szabo, "New methods for measuring imbibition capillary pressure and electrical resistivity curves by centrifuge," $S P E$ Journal, vol. 14, no. 14, pp. 243-252, 1974.

[12] G. T. Toledo, R. A. Novy, H. T. Davis, and L. E. Scriven, "Capillary pressure, water relative permeability, electrical conductivity and capillary dispersion coefficient of fractal porous media at low wetting phase saturation," SPE Advanced Technology Series, vol. 2, no. 1, pp. 136-141, 2013. 
[13] K. Li and W. Williams, "Determination of capillary pressure function from resistivity data," Transport in Porous Media, vol. 67, no. 1, pp. 1-15, 2007.

[14] D. G. Longeron, M. J. Argaud, and L. Bouvier, "Resistivity index and capillary pressure measurements under reservoir conditions using crude oil," in SPE Annual Technical Conference and Exhibition, San Antonio, Texas, October 1989.

[15] X. Ge, Y. Fan, S. Deng, and Q. Du, "Research on correlation between capillary pressure and resistivity index based on fractal theory," Journal of China University of Petroleum, vol. 36, no. 4, pp. 72-76, 2012.

[16] J. Hofman, W. Slijkerman, W. Looyestijn, and Y. Volokitin, "Constructing capillary pressure curves from NMR log data in the presence of hydrocarbons," in SPWLA Annual Logging Symposium, Oslo, Norway, 1999.

[17] Y. He, Z. Mao, L. Xiao, and Y. Zhang, "A new method to obtain capillary pressure curve using NMR T2 distribution," Journal of Jiling University, vol. 35, pp. 177-181, 2005.

[18] X. Ge, Y. Fan, F. Wu, and P. Huang, "Correspondence of core nuclear magnetic resonance T2 spectrum and resistivity index," Journal of China University of Petroleum, vol. 36, no. 6, pp. 53-61, 2012.

[19] Y. H. Guo, B. Z. Pan, L. H. Zhang, and C. H. Fang, "Research and application of the relationship between transverse relaxation time and resistivity index in tight sandstone reservoir," Journal of Petroleum Science and Engineering, vol. 160, pp. 597-604, 2018.

[20] C. Feng, Z. Yang, Z. Feng, Y. Zhong, and K. Ling, "A novel method to estimate resistivity index of tight sandstone reservoirs using nuclear magnetic resonance logs," Journal of Natural Gas Science and Engineering, vol. 79, p. 103358, 2020.

[21] F. Liu, X. Zhu, L. Yang, L. Xu, X. Niu, and S. Zhu, "Sedimentary characteristics and facies model of gravity flow deposits of late Triassic Yanchang formation in southwestern Ordos basin, NW China," Petroleum Exploration and Development, vol. 42, no. 5, pp. 633-645, 2015.

[22] K. X. Xiao, The researching of the characteristic and main controlling factors of Chang-8's oil reservoir in Jiyuan area, Ordos basin, Chengdu University of Technology, 2011.

[23] H. Yang and W. Z. Zhang, "Leading effect of the seventh member high-quality source rock of Yanchang formation in Ordos basin during the enrichment of low-penetrating oil-gas accumulation: geology and geochemistry," Geochimica, vol. 34, no. 2, pp. 147-154, 2005.

[24] C. Feng, Y. Shi, J. Li, L. Chang, G. Li, and Z. Mao, "A new empirical method for constructing capillary pressure curves from conventional logs in low-permeability sandstones," Journal of Earth Science, vol. 28, no. 3, pp. 516-522, 2017.

[25] C. Feng, Z. Wang, X. Deng et al., "A new empirical method based on piecewise linear model to predict static Poisson's ratio via well logs," Journal of Petroleum Science and Engineering, vol. 175, pp. 1-8, 2019.

[26] P. Zhao, Z. Sun, X. Luo et al., "Study on the response mechanisms of nuclear magnetic resonance (NMR) log in tight oil reservoirs," Chinese Journal of Geophysics, vol. 59, pp. 19271937, 2016.
[27] L. Zhu, C. Zhang, Y. Wei, and C. M. Zhang, "Permeability prediction of the tight sandstone reservoirs using hybrid intelligent algorithm and nuclear magnetic resonance logging data," Arabian Journal for Science and Engineering, vol. 42, no. 4, pp. 1643-1654, 2017.

[28] P. Zhao, Z. Wang, Z. Sun, J. Cai, and L. Wang, "Investigation on the pore structure and multifractal characteristics of tight oil reservoirs using NMR measurements: Permian Lucaogou Formation in Jimusaer sag, Junggar Basin," Marine and Petroleum Geology, vol. 86, pp. 1067-1081, 2017. 